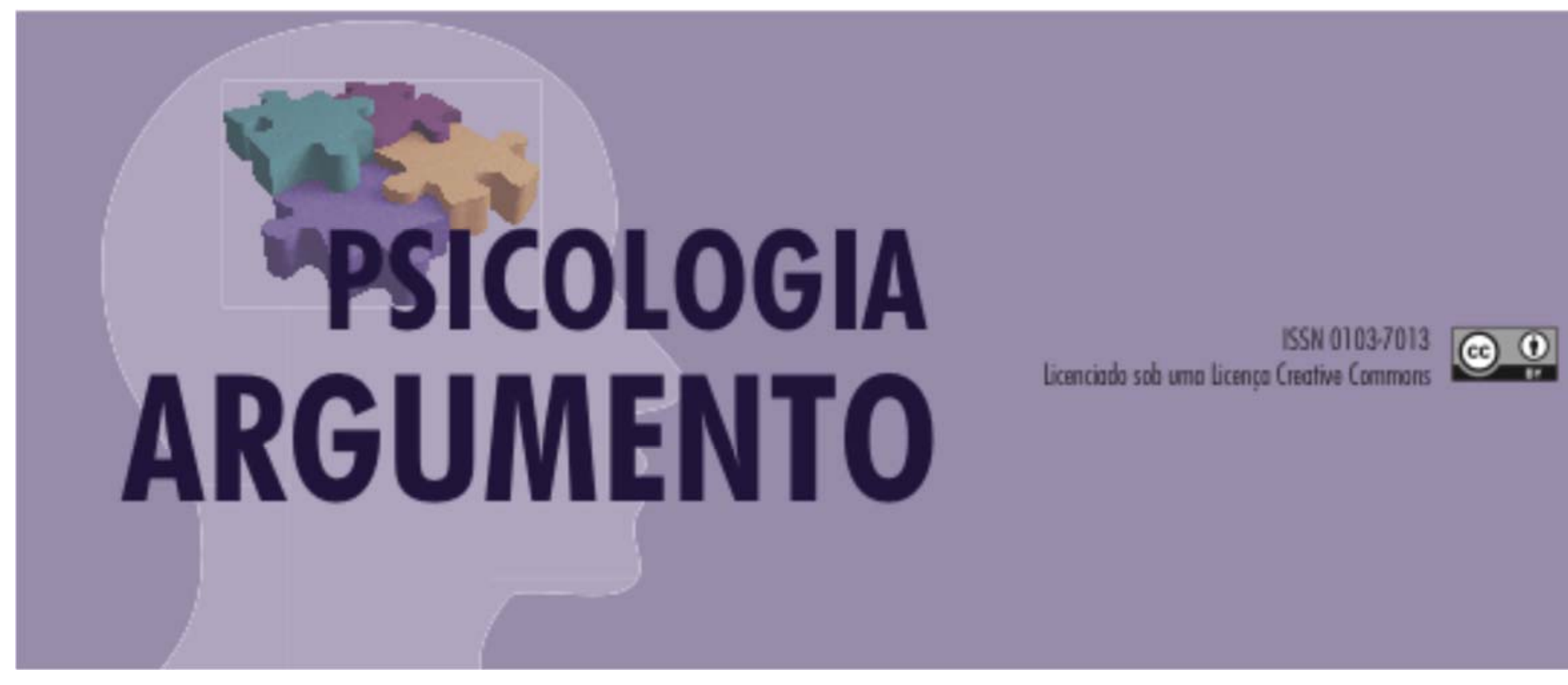

doi: http://dx.doi.org/10.7213/ psicolargum.36.94.AO02

\title{
Política de acesso e identidade: Rodas de Conversa produzindo sentido entre universitários
}

\section{Education Policy and identity: conversation circles promoting meaning to students}

\author{
Michelle Tomassini Jacques[ $\left.{ }^{[}\right]$ \\ [a] - Aluna do Programa de Pós-Graduação em Psicologia -Mestrado em Psicologia da linha Educação, \\ Trabalho e Produção de Subjetividade. \\ Universidade Federal do Paraná, Curitiba, PR, Brasil. E-mail: michellejacquesg@gmail.com
}

Miriam Aparecida Graciano Souza Pan[ $\left[{ }^{\mathrm{b}}\right]$

[b] Professora, pesquisadora do Programa de Pós-Graduação em Psicologia - Mestrado em Psicologia da linha Educação, Trabalho e Produção de Subjetividade, da Universidade Federal do Paraná. E do Programa de Pós-

Graduação em Educação - Doutorado na Educação da linha de pesquisa em Cognição, Aprendizagem e

Desenvolvimento Humano da Universidade Federal do Paraná, Curitiba, PR, Brasil. E-mail:

miriamagspan@yahoo.com.br

\section{Resumo}

O objetivo deste trabalho foi analisar os efeitos de sentido de uma política de ocupação de vagas remanescentes da UFPR intitulado PROVAR na produção da subjetividade de um grupo de estudantes, seus beneficiários. Utilizou-se da metodologia de Rodas de Conversas, proposta pelo Projeto PermaneSendo, do departamento de Psicologia da UFPR. As Rodas de Conversa possibilitaram espaços para a circulação da palavra entre os estudantes, promovendo a troca de experiências e o diálogo sobre as dificuldades encontradas ao longo da trajetória universitária. Promoveu-se a construção de estratégias de enfrentamento das contradições encontradas nas políticas institucionais de inclusão, em seus efeitos subjetivos, refletidos e vivenciados nas práticas acadêmicas cotidianas. Cinco estudantes do curso de psicologia, ingressantes à UFPR pelo PROVAR participaram dessa pesquisa. A entrada ao ensino superior público por meio do PROVAR mostrou-se ser uma experiência frustrante e solitária, com o 
sentimento de falta de mérito pela forma de ingresso, reafirmando sentimentos de exclusão na inclusão. Os encontros possibilitaram a construção de estratégias de enfrentamento das contradições encontradas nas políticas institucionais inclusivas fortalecendo um coletivo de apoio desse grupo, o que favoreceu a ressignificação dos sentidos da identidade do estudante PROVAR e seu pertencimento à instituição.

Palavras-chave: Universidade; Identidade; Subjetividade; Ensino Superior Público; estudantes.

\begin{abstract}
The objective of this study was to analyze subjectivity produced in a group of five students who entered public university through a governmental policy (PROVAR) which aims at occupying vacancies in a public University in the state of Paraná. The methodology used in this study was conversation circles as proposed by an intervention Project known as PermaneSendo, created at the Psychology department at the Federal University of Paraná (UFPR), in response to a Federal Government inclusion and permanency program for public universities. The conversation circles permitted the participants to share their personal experiences promoting dialogue and experience sharing about the difficulties encountered throughout university life. The circles promoted strategies for coping with contradiction found in public inclusion policies and their subjective effects on students. The results showed that students who entered UFPR through PROVAR suffered from exclusion, despair, isolation and lack of merit as a result of their form of entry. The circles allowed the participants to find new meaning and sense of belonging to the university.
\end{abstract}

Keywords: university; identity; subjectivity; public university; students.

\title{
Resumen
}

El objetivo de este estudio fue analizar el significado subjetivo producido en un grupo de cinco estudiantes que ingresaron a la universidad pública a través de una política gubernamental conocida como PROVAR. La política tiene como objetivo ocupar vacantes en la universidad pública del estado de Paraná. La metodología utilizada en este estudio fue la de los círculos de conversación, propuesto por un Proyecto de intervención llamado PermaneSendo, creado en el departamento de psicología de la Universidad Federal de Paraná (UFPR), en respuesta a un programa de inclusión y permanencia del Gobierno Federal para universidades públicas. Los círculos de conversación permitieron a los participantes compartir sus experiencias personales como estudiantes a otros homónimos, promoviendo el diálogo y el compartir sus experiencias sobre las dificultades encontradas en la vida universitaria. Los círculos promovieron la creación de propuestas para confrontar la contradicción que se encuentra en las políticas de inclusión pública y sus efectos subjetivos en los estudiantes que se reflejan en las prácticas académicas institucionales. Se realizaron dos círculos de conversación. Los resultados mostraron que los estudiantes que ingresaron a la UFPR a través de PROVAR sufrieron exclusión, desesperación, aislamiento y falta de mérito por su forma de ingreso. Los estudiantes evalúan su experiencia como estudiantes públicos como frustrante y solitaria. Los resultados encontrados posibilitan la construcción estrategias y programas de apoyo para contrarrestar esta situación y la creación de círculos de apoyo que permitieron a los estudiantes PROVAR encontrar un nuevo sentido de pertenencia a la universidad.

Palabras clave: Universidad; Identidad; Subjetividad; Educación superior pública; estudiantes

\section{Introdução}

As universidades brasileiras passam por reestruturações importantes desde a década de 1990, sob efeito de discursos como democratização do acesso, inclusão, diversidade, ampliação 
do acesso à populações e grupos historicamente excluídos, etc. Neste contexto, foi criado o Programa de Ocupação de Vagas remanescentes (PROVAR) da Universidade Federal do Paraná (UFPR), em 2004, sob a Resolução 95/03 CEPE, pelo Conselho De Ensino, Pesquisa E Extensão. Trata-se de uma política de mobilidade acadêmica, cujo objetivo é a ocupação de vagas ociosas dos cursos de graduação da Universidade. Suas etapas foram restabelecidas em 2009 pela resolução 99/09 - CEPE e compõem duas fases, as quais ocorrem sobre a responsabilidade da Pró-Reitoria de Graduação (PROGRAD) e das coordenações de curso. Embora essa política estudantil vise a inclusão de estudantes, há a necessidade de entender o sentido dessa experiência para eles, especificamente daqueles transferidos de universidades particulares, sendo essa uma das fases do PROVAR.

Algumas questões relacionadas à integração e ao apoio psicológico oferecidos aos estudantes, bem como a qualidade da permanência precisam ser (re)avaliadas e discutidas a fim de analisar o efeito dessa política pública na constituição da identidade profissional dos mesmos, ou seja, quais os sentidos atribuídos aos estudantes que ingressam pelo referido programa? De acordo com Baibich-Faria e Arco-Verde (2006), "Diversas reações, algumas das quais ligadas a precarização da universidade pública foram expressas pela comunidade acadêmica, durante a elaboração e apreciação da nova proposta” (p. 3), assim como após sua aprovação.

O discurso (de desaprovação) pôde ser percebido nas práticas existentes quando se tratava da aceitação e inserção dessa população na universidade. Muitos dos estudantes que ingressam pela transferência externa do PROVAR acabam sendo invisíveis e sem apoio para lidar com as diversas dificuldades que encontram. "O espaço subjetivo concedido a alguns destes jovens acaba passando de uma total invisibilidade a um tipo de visibilidade destacada pelo fracasso e abandono, ou pelo excesso de empenho para assegurar resultados positivos em seus estudos (Pan, 2013, p. 4).

Mudanças na esfera do ensino superior brasileiro, tanto no sentido positivo quanto negativo, não podem ser discutidas e analisadas sem serem levadas em conta as mudanças que ocorrem na sociedade. “Tal empreendimento não se faz sem relacionar essa instituição com o conjunto da sociedade, na ótica de sua dimensão política” (Fávero, 2006 p. 5). A referida autora convoca a universidade a ser um campo de debate, onde os problemas são analisados e discutidos, e onde as propostas de melhoramento devem ser visadas e analisadas criticamente. 
Portanto, a preocupação central deste artigo é analisar a configuração dos discursos de identidade no contexto da universidade pública, e seus efeitos subjetivos sobre os ingressantes pela política do PROVAR.

\section{Identidade}

Segundo Pan (2003), as identidades são constituídas historicamente por meio dos modos de subjetivação, produzido pelos discursos que configuram as relações sociais. A cultura, a política, as questões sociais e econômicas influem diretamente sobre os modos de produção da subjetividade de um grupo social em um determinado período histórico, o que não nos permite mais pensar em identidade de modo estático e unitário, mas sim, em sua multiplicidade e em processo de constante transformação. Não se tem uma única identidade, mas sim várias identidades, dependendo do contexto e das relações existentes. Trata-se de um processo situado cultural, institucional e historicamente (Pan, 2003; Hall, 2014). Sawaia (2001) afirma ser necessário identificar as motivações por trás das identificações, pois através delas criam-se defesas e estratégias de enfrentamento ao desconhecido. Há a formação de grupos identitários que buscam em sua união se proteger, como há também a criação de grupos visando a descriminação e separação. Face ao desconhecido e daquilo que não é dominado, o sujeito acaba por perder sua capacidade de controle, gerando ansiedade, agressão e insegurança.

Conflitos sociais ocorrem, não pela luta ao direito à diferença, mas pelo fato dos fenômenos como os de gênero, de religionalismos, de classe, racionais e étnicos estarem atravessados pela ideia da "identidade etiqueta" (Sawaia, 2001, p. 121) e com isso, vistos através de um olhar defensivo e/ou agressivo, gerando segregação e a busca pela dominação em nome do poder. Identidade é conceito político ligado ao processo de inserção social em sociedades complexas, hierarquizadas e excludentes, bem como ao processo de inserção social nas relações internacionais. O clamor pela identidade, quer para negá-la, reforçá-la ou construíla é parte do confronto de poder na dialética da inclusão/exclusão e sua construção ocorre pela negação dos direitos e pela afirmação de privilégios. Ela exclui e inclui parcelas da população dos direitos de cidadania, sem prejuízo à ordem e harmonia social. O medo do desconhecido gera a necessidade da criação de identidades polarizadas, pois através da criação de papeis estáticos, posições consideradas privilegiadas, parecem permanecer asseguradas (Sawaia, 2001). 
O produto da insegurança é o medo excessivo da transformação. Aquela é gerada quando ocorre a quebra de significações dominadoras. Na percepção de que aquele lugar privilegiado, porém separatista e alienante, não é de direito do outro - o diferente e desconhecido, gera-se atos de discriminação, exclusão e indiferença. Um olhar dialético é necessário ao referir-se à identidade. Através da manutenção da tensão entre os dois sentidos da identidade - o de permanência e o de transformação - me identifico com um grupo, mas ao mesmo tempo me transformo conforme os sentidos criados no decorrer das minhas vivencias (Sawaia, 2001).

Um olhar dialético também se faz necessário ao analisar as políticas diferenciadas de acesso, referindo-se especificamente à educação no ensino superior público e os programas educacionais criados que buscam atender a grupos excluídos dos mais variados âmbitos da sociedade, sob o discurso da inclusão, pois esta constitui-se como par dialético da exclusão.

O ingresso à universidade constitui-se importante na constituição de identidade profissional, bem como na possibilidade de instrumentalizar os estudantes para a reflexão a respeito das práticas institucionais presentes no seu cotidiano acadêmico, especificamente ao se tratar do acolhimento e inclusão, livre de preconceito, objetivando para uma formação voltada a práticas mais humanizadoras. A universidade, por ser um espaço que convive com a diversidade e com uma crescente heterogeneidade (Pan, 2013), precisa se atentar a fenômenos velados de preconceito e exclusão. Alguns exemplos são a amputação de direitos, reações de indiferença e falta de legitimação dos indivíduos e suas culturas, atitudes que negam às injustiças sociais, além do fenômeno do "racismo institucional”, (Baibich-Faria \& Arco-Verde, 2006, p. 11) o qual “inclui manipulação ou tolerância de políticas institucionais, de natureza intencionais ou não intencionais, que injustamente restringem as oportunidades dos gruposalvos” (p. 12).

\section{Preconceito e exclusão}

O preconceito é uma temática recorrente no âmbito do ensino superior. Baibich-Faria e Arco-Verde (2006), buscavam elucidar como o preconceito se dava no ensino superior público, em referência específica ao primeiro grupo de estudantes transferidos pelo PROVAR no curso de Letras da UFPR. A esperança de ensinar o “antipreconceito” (p, 11) foi o objetivo principal das autoras, as quais apontam para vários fenômenos considerados preconceituosos, 
discriminatórios. O racismo aversivo, também foi levantado, sendo este "uma forma sutil e contemporânea de preconceito racial” (p. 12). Para as referidas autoras (2006), a denúncia é um dos passos rumo a mudanças junto à comunidade acadêmica.

O espaço do não-lugar foi percebido à medida que esses novos alunos encontravam dificuldade para se localizar dentro da própria universidade, além de obterem dificuldade quando buscavam informações por falta de vontade dos informantes, esses sendo alunos e frequentadores da própria universidade. Essa falta de mapas e orientações, os quais possibilitariam que os novos alunos caminhassem com suas próprias pernas é uma forma de abortamento daquilo que é percebido como estranho pelo sistema, nesse caso, os novos integrantes à universidade pública. “Assim, ser idêntico, isto é, pertencer ao grupo dos iguais é simbolicamente sonegado ao aluno que ingressa pelo PROVAR” (Baibich-Faria \& Arco-Verde, 2006, p. 5). Constata-se a tentativa do sistema de excluir, mesmo quando diz incluir.

Barreiras não visíveis, porém concretas são instituídas a fim de evitar que aqueles que entraram pelas portas dos fundos ascendam ao uso da marca UFPR através da mistificação do vestibular e pela desqualificação da bagagem trazida das instituições de ensino superior de origem (Baibich-Faria \& Arco-Verde, 2006). Para as referidas autoras o estudante transferido pelo PROVAR é percebido como não pertencente, rejeitado, diferente, aluno dito especial. “(...) ao espaço do não-lugar e ao não-ser, se junta o não compartilhamento da marca que enaltece o grupo”. (p.7) “Até a existência do preconceito pode ser justificada, atribuindo-se sua existência à responsabilidade do perseguido. Tratar a vítima como se fosse responsável pelo fato de ser discriminada” (p. 7).

A falta de ajuda para sanar problemas básicos como matrículas, carteiras de estudantes, prazos, etc. foram assuntos também surgidos nas entrevistas realizadas pelas autoras acima citadas. O que ocorreu foi a ajuda entre os iguais, ou seja, aqueles que eram do PROVAR ajudavam-se uns aos outros. “A solidariedade no sofrimento mostra que há ajuda entre os iguais” (Baibich-Faria \& Arco-Verde, 2006, p. 9).

Todavia, evidenciar ou compreender os efeitos discursivos na constituição de identidades e nos diferentes modos de subjetivação requer compreender a voz do estudante como resposta ativa ao grupo social - a arena institucional (Machado, 2011). Há de se levar em consideração as relações entre os estudantes vindos pelo PROVAR e os demais membros que compõem a universidade. 
Portanto, esse estudo elege como objeto de investigação os efeitos dos discursos de identidade atribuídos aos estudantes transferidos pelo PROVAR, dando visibilidade às contradições da política em seus efeitos subjetivos. Especificamente, objetiva-se promover, por meio de Rodas de Conversas, a criação de um espaço de reflexão que possibilite a construção de estratégias de apoio coletivo a esse grupo de estudantes.

\section{Materiais e método}

Está é uma pesquisa-intervenção de fundamentação bakhtiniana. A pesquisaintervenção considera a importância de se estar imerso no seu contexto investigativo, a fim de poder interagir-se diretamente no processo, conhecendo os dois lados envolvidos, o do pesquisador e dos estudantes universitários. A observação não pode se situar fora do mundo observado, de modo que o pesquisador precisa ser parte integrante do objeto observado, (Pan, 2016). Assim, a participação de eventos que se observa, como parte integrante da realidade, produz no campo da pesquisa uma voz, esta sendo a do pesquisador, o qual se encontra com a arena de vozes dos participantes. Com isso, a imersão no contexto da pesquisa auxiliou-nos no melhor entendimento da produção dos efeitos e sentidos da experiência acadêmica. Tal concepção de pesquisa fundamentada nos estudos bakhtinianos se consolidaram na psicologia brasileira por meio de pesquisadores como Amorim (2002), Jobim e Souza (2012), Freitas (2002; 2009) e outros. No campo da psicologia educacional, particularmente no estudo com universitários este desenvolveu-se e vem se consolidando com as pesquisas desenvolvidas por Pan, (2003); Machado e Pan, (2012); Machado e Pan (2013); Machado e Pan (2014), Machado e Pan, (2016); Pan, Zonta e Tovar, (2015); Branco e Pan, (2016), sendo aplicados no contexto universitário.

A presente pesquisa foi realizada na Universidade Federal do Paraná, entre os meses de março de 2014 a fevereiro de 2015. Insere-se no Projeto intitulado Identidade, Política e Universidade Contemporânea: desafios à Psicologia brasileira (Pan, 2013), registrado na Plataforma Brasil (CAAE: 60107016.4.0000.0102) (Número do Parecer: 1.858.494).

O Projeto foi intitulado e reconhecido pela comunidade estudantil em sua dimensão de extensão como PermaneSendo (Pan, 2016).

\section{Participantes}


Participaram dessa pesquisa cinco estudantes brasileiras, do sexo feminino, com idades entre 20 e 35 anos, todas ingressantes pela transferência externa do PROVAR, ao curso de Psicologia da UFPR, sendo esse o critério de inclusão para a participação dessa pesquisa.

Os nomes completos das participantes, assim como dos entrevistadores foram substituídos por nomes fictícios, sendo eles:

Estudante 1 - Jane | Estudante 2 - Julia Bete | Estudante 3 - Fabia | Estudante 4 - Gina | Pesquisador- Mari

O processo de investigação - interventiva: Rodas de Conversa

As Rodas de Conversa, constituem-se estratégias de acolhimento grupal em busca de consolidação de coletivos de apoio constituindo enquanto um modelo de tutoria por pares, desenvolvida sob orientação baktiniana. Buscam oferecer um espaço dentro da universidade onde os estudantes podem compartilhar seus desafios, dificuldades, sofrimento, experiências e superações, aspectos esses que muitas vezes são carregados de forma isolada e sofrida pelos estudantes, sendo poucos os espaços oferecidos para esse compartilhamento (Pan, 2013).

A ação possibilita a presentificação dos sujeitos, das suas narrativas e o compartilhar de experiências. Possibilita a fala e escuta entre os pares através da circulação da palavra, e, a partir disso, a reflexão (e ação) sobre as possibilidades de atuação frente às necessidades surgidas pelos estudantes, promovendo o engajamento dos universitários.

A abertura da Roda de Conversa ocorreu com a explicação acerca dos objetivos e propósitos dos encontros, sendo esse o espaço para que as estudantes pudessem falar sobre o sentido de suas experiências e dificuldades acadêmicas, objetivando dar lhes voz, através de um espaço dialógico, por meio de debates e conversas das necessidades e expectativas ao longo da jornada acadêmica, possibilitando ressignificações dessas vozes, assim como a produção de novos sentidos, promovendo a permanência, de forma menos sofrida, na universidade (Pan, 2013).

Realizou-se duas Rodas de Conversa, cada uma com duração de aproximadamente uma hora. As Rodas de Conversa foram denominadas de: R1, e R 2.

Termos de Consentimento Livre e Esclarecido (TCLE) formam apresentados e explicados às participantes, as quais assinaram e receberam uma cópia dos mesmos. 


\section{Registro e análise dos dados}

As duas Rodas de Conversas foram gravadas, conforme autorização das estudantes participantes e transcritas na sua totalidade.

Segundo Brait (2006), as contribuições teórico-metodológicas do pensamento bakhtiniano constituem um conjunto de "conceitos, noções e categorias que especificam a postura dialógica diante de corpus discursivo, da metodologia e do pesquisador” (p. 61). A relevância de uma perspectiva dialógica ocorre pela análise das "especificidades discursivas constitutivas de situações em que a linguagem e determinadas atividades se interpenetram e se interdefinem” (p. 61), além do compromisso ético do pesquisador com o sujeito histórico - seu objeto de pesquisa.

Noções do outro e de sua importância na reflexão sobre a linguagem podem ser compreendidos por meio de conceitos bakhtinianos como alteridade, dialogismo, polifonia, heterogeneidade, interdiscursividade e intertextualidade (Brait, 2006). O conceito de dialogismo é constitutivo de qualquer discurso, porém contendo dimensões diferentes em discursos específicos, tais diferenças produzem efeitos de sentidos diferentes. Portanto, a partir da análise enunciativa e sua consequente explicitação de posicionamento se pode perceber as diversas vozes presentes nos discursos sociais e suas consequentes produções de sentidos e identidades.

Com isso, propôs-se analisar os discursos de identidade e o sentido da experiência de ser um estudante transferido à UFPR pelo PROVAR e seus efeitos na produção de subjetividades desses estudantes. Contudo, a reprodução, aqui, desses dados passa pelo processo de reconstrução ao falar-se do outro. Pan (2013) explica que segundo Bakhtin, a palavra carrega valores de uma determinada sociedade. Através da palavra evidenciam-se os modos como esses valores explicam-se e confrontam-se. Portanto, buscou-se promover discussões acerca dos sentidos construídos, os quais dizem dos lugares sociais que esses estudantes ocupam na universidade pública.

\section{Resultados e discussões}

A Transição: obstáculos e superações 
As estudantes relatam como o processo de transferência pelo PROVAR foi uma experiência de aprendizagem e um desafio. Para elas, a sensação foi de apreensão, mas também de felicidade. Afinal, para algumas já era a terceira tentativa de ingresso, enfim conquistado. Após regularização das candidatas, o próximo passo seria o processo de equivalências, e com essa etapa, surgiram novas surpresas, segundo elas, desagradáveis, pois ao contrário do que constava em edital, (conforme RESOLUÇÃO Nº 99/09-CEPE), a maioria das equivalências foi praticamente nula. As estudantes não esperavam ter de repetir "tantas disciplinas”, conforme ocorreu (R1). Todavia, elas marcam a importância das longas filas na coordenação à espera de suas equivalências, o que possibilitou encontros, amizades e união entre as novas ingressantes.

A justificativa, conforme relatam as estudantes, era que a UFPR não poderia comprovar a qualidade de ensino de algumas das outras instituições, bem como priorizava a pesquisa, portanto não concedia equivalências além daquelas dadas às estudantes. Por fim, após as longas esperas, as disciplinas a serem cursadas eram listadas e entregues as estudantes, "sem possibilidade de esclarecimento e/ou questionamento" (R2). Afirmam que não tinham sequer a oportunidade de escolha dentre as disciplinas e de horários, pois precisavam se encaixar nas “sobras das vagas” (R2) de cada período disponível. Essas disciplinas eram cada uma em uma turma, período e horários diferentes.

(R.2) Julia Bete. - .. “E o que me deixou mais assim mal é porque quando... a gente fez o PROVAR, ((fala truncada)) leu todos os termos e falar o que a gente tinha que concordar, tava dizendo lá de que, de preferência seria colocado no mesmo ano e no mesmo período que ele já estava cursando”.

Ao falar sobre suas vivências em relação às equivalências, Julia Bete demonstra sua apreensão e tensão ao compartilhar sua experiência.

As estudantes explicam que o Índice de Rendimento Acadêmico (IRA) é o critério adotado pela instituição para distribuição de oportunidades de pesquisa, estágios, disciplinas, etc. mediante concorrência durante as devidas seleções. Por meio das supostas boas notas, os alunos aumentam seus IRAs. No entanto, ao se tratar das transferências externas à universidade, esse critério modificou-se durante a trajetória das estudantes, com a mudança de coordenação, novos critérios foram estabelecidos e as equivalências concedidas às estudantes passaram a não mais considerar as notas das disciplinas cursadas nas universidades de origem. 
Portanto, o estudante teria o direito à equivalência de determinada disciplina, todavia sua nota seria apagada, omitida, zerada. Ao desconsiderar-se (omitir) a nota do estudante transferido pelo PROVAR nas equivalências, argumentou-se que esses estudantes deveriam “construir (meritocracia) seus IRAs na UFPR” (R1). Nesse caso, o estudante transferido pelo PROVAR jamais conseguiria alcançar seu colega ingressante pelo vestibular tradicional, o qual tem suas notas computadas no sistema desde seu primeiro semestre, portanto o estudante transferido pelo PROVAR também jamais teria preferência em qualquer atividade obrigatória, ou disciplina, pois nunca teria conseguido construir seu IRA da mesma forma que seus outros colegas tiveram a oportunidade de fazê-lo.

Tal ação amplia ainda mais a distância que esses estudantes teriam em relação aos seus colegas veteranos, gerando o sentido de incapacidade e desmerecimento. Pode-se dizer que o IRA ocupa a função de classificação, justificado no discurso do mérito possibilitando ou dificultando certas vantagens aos estudantes da referida instituição.

A falta de normas consistentes, as quais regulamentariam a forma como as equivalências seriam concedidas, reforça o sentimento de desamparo, pois as regras do jogo dependem da visão e entendimento do professor que ocupa o cargo de coordenação, este sendo temporário e rotativo. Constata-se uma arbitrariedade no processo de equivalências dos estudantes transferidos pelo PROVAR, pois marca-se a diferença entre o estudante que ingressa de forma supostamente legítima e o que o entra pelas "porta-dos-fundos” (Baibich-Faria \& Arco-Verde, 2006, p.7). Esse processo arbitrário de concessão de equivalências reforça o sentimento e experiência de confusão, insegurança e contradição vivenciada por estas estudantes. Julia Bete explica seu sentimento de desamparo: (R. 1) "Só que aqui, mesmo a gente não pagando não teve nenhum tipo de apoio ... a gente teve muitos problemas com as equivalências de matérias, eu...vi exatamente a mesma coisa e tava sendo torturante".

As estudantes contam que já entraram atrasadas em relação às outras turmas, pois as aulas já haviam começado há uma semana na ocasião das matriculas de quem havia ingressado via PROVAR. As confraternizações entre os veteranos e os calouros (ingressantes pelo vestibular) já tinham ocorrido, assim como as matriculas e as aulas. As estudantes não puderam participar da semana de recepção dos calouros onde há o acolhimento pelos colegas e pela instituição, sendo um espaço onde também há o repasse de informações importantes para uma melhor transição à vida acadêmica. 
As estudantes explicam (R.1) que a distribuição das vagas das disciplinas ocorre no início do semestre, por meio de sistema e posteriormente, conforme necessidade, na coordenação. Todavia, os procedimentos de praxe não ocorrem da mesma forma para os estudantes que ingressam pela transferência externa, pois esses ingressam após o início do semestre e precisam ser encaixadas nas vagas que não foram ocupadas pelos estudantes já matriculados, contribuindo para a desperiodização das novas integrantes, assim como a dificuldade de se integrarem a uma mesma turma e consequentemente de fazerem amizades e sentirem-se parte de um grupo.

As estudantes transferidas pelo PROVAR lamentam não terem tido a oportunidade de vivenciarem o rito de passagem, a recepção e festividade comum dos calouros ao entrarem na universidade. Para elas, esse é um momento importante onde imaginam serem oficialmente reconhecidas, onde receberiam informações sobre a jornada acadêmica e onde sentiriam incluídas no sistema. Para elas, isso é algo que marca negativamente a entrada à universidade pública, assim como contribui para o sentimento de isolamento.

(R. 1) Fabia. - "Eu acho que a prova do PROVAR deveria ser... é... junto com o vestibular... porque normalmente na semana do calouro eles passam as informações e tudo, a gente acaba pulando essa etapa das ... informações básicas mesmo, né?”

Além de não serem formalmente recebidas pela instituição, nem apresentadas aos seus colegas, não conheciam as instalações e procedimentos internos da instituição. Não houve esclarecimento sobre o funcionamento e aquisição das carteiras de identificação estudantil (de uso obrigatório para acesso aos serviços da UFPR), da biblioteca, das obrigações e deveres acadêmicos, etc. As estudantes contam que se sentiram totalmente perdidas e confusas, pois não conheciam as salas, o sistema, nem os professores. "Tinham que se virar” para encontrar seus lugares. Elas contam que esse funcionamento contribuiu ainda mais para o "sentimento de isolamento", pois a cada sala que frequentavam, havia um grupo de pessoas diferentes, os quais já se conheciam em sua grande maioria e já tinham seus grupos fechados para estudo e trabalhos acadêmicos (R1).

Outra discussão importante que surgiu nas rodas de conversa foi a integração social. As ingressantes do PROVAR relatam muita dificuldade para se inserirem quando precisavam realizar trabalhos acadêmicos em duplas ou em grupos. Não eram aceitas, pois seus colegas lhes diziam que "não as conheciam, nem seus modos de estudar e realizar trabalhos” (R. 1). 
Percebe-se a exclusão dos novos integrantes por meio do discurso da possível incompetência e desvalorização pela forma de ingresso, reforçando a exaltação da grife Federal, conforme Baibich-Faria e Arco-verde (2006).

(R.1) Fabia - "Eu tinha muita dificuldade no início, principalmente pela questão de trabalho, de querer me inserir em alguns grupos assim, por necessidade de fazer o trabalho $e$ de pessoas negarem mesmo, mesmo tendo espaço ainda. De negar, porque não me conheciam... como eu não era acolhida no grupo, na maioria dos grupos eu acabava tendo que fazer trabalho com pessoas que não fazem o trabalho, aquelas pessoas que também restam no grupo... e eu achava que não iria encontrar isso aqui (risos)".

As ingressantes do PROVAR assinalam o choque que sentiram ao se depararem com a falta de integração e aceitação presente na universidade daqueles que já foram deixados de lado, daqueles considerados sem mérito, assim como “os estudantes mais velhos” (R.2). As estudantes relatam que esperavam encontrar um grupo de acadêmicos receptivos e acolhedores, porque a final, para elas, "tratava-se de um curso de psicologia e psicologia é acolhimento" (R.1), mas, segundo Julia Bete não foi isso que ocorreu, nem por parte dos acadêmicos, tampouco por parte da instituição. Julia Bete compara sua experiência anterior em uma universidade privada onde ela foi acolhida e presenciou solidariedade por parte dos colegas (R. 2). Julia Bete fala do sentimento de exclusão que sentiu, o qual foi compartilhado por outras estudantes ingressantes pelo PROVAR.

(R. 1) Julia Bete - "É... eu acho que quem vem pra cá sente esse choque, né, na questão de tudo, não só na universidade ((ruído)), questão de tudo..."

(R.1) Jane - "Fiquei três períodos trancados, eu voltei em outra turma ... uma turma que não me conhecia...e eles já tavam também no meio do curso, no terceiro período, no mesmo período que entrei aqui e desde o primeiro dia ... desde o primeiro dia, nunca fui excluída por parte do grupo e da questão da sala de aula”.

Fabia, vinda de outra cidade e beneficiaria de uma política pública voltada a concessão de auxílio financeiro aos estudantes, relata os obstáculos que enfrentou ao ligar na Pró-Reitoria de Assuntos Estudantis em busca de maiores informações sobre os procedimentos e requisitos para o recebimento da Bolsa Permanência. Ela compartilha com o grupo o constrangimento que sentiu “ao ser questionada por uma das atendentes sobre o verdadeiro motivo dela estar em 
Curitiba" (R. 1). A estudante relata ter sido "acusada de vir a Curitiba a turismo, de não ter os motivos certos por estar na cidade e de vir tirar a vaga de quem realmente merece”.

(R.1) Fabia “(...) quase fiz as malas e voltei pra minha casa... a mulher me tratou muito mal, perguntou da onde eu era... daí ela falou, “"mas na sua cidade, mas no seu Estado não tem universidade pública? Porque vocês que vem de outro Estado pra cá vocês vem fazer turismo, tirar nota baixa, tirar bolsa dos outros, bolsa das pessoas do Paraná, tem rendimento baixo"”...

Machado e Pan (2016) discorrem sobre a vergonha, falta de mérito, culpa e tensão, sentimentos esses compartilhados por estudantes que, por meio de práticas institucionais excludentes “diferencia objetivamente e subjetivamente” (p. 485) seus beneficiários, mantendo-os fixados em discursos de identidade do não merecedor e do não qualificado, contribuindo para o sentimento de não pertencimento e exclusão.

A exclusão ocorre também por meio da amputação de direitos, reações de indiferença e falta de legitimação do PROVAR (Baibich-Faria \& Arco-Verde, 2006). A falta de aprovação dessa política de ingresso, por parte de alguns membros da instituição, pode ser observada por meio de ações praticadas, como a falta de acolhimento das estudantes, o dificultamento de integração das candidatas habilitadas, no semestre e ano adequado do respectivo curso. $\mathrm{O}$ sistema inclui os estudantes, mas ao mesmo tempo exclui-os ao negar lhes a equivalência, reconhecimento formal e acolhimento.

A grife federal descrita por Baibich-Faria e Arco-Verde, (2006) sinaliza a desvalorização de conhecimentos adquiridos fora da Universidade Federal. Esses fenômenos também foram relatados nas narrativas das estudantes.

Insegurança, confusão e ameaça são sentimentos que afirmam o sentido de exclusão vivido pelo grupo, em especial, o valor atribuído ao aluno Federal em comparação com aqueles que “não se sabe bem de onde vem”.

A entrada à universidade já evidencia um “processo de estranhamento” (Pan, et al. 2014, p. 7), o qual pode gerar sofrimento, dúvidas e confusão. Ao falar sobre o sentimento de exclusão uma das estudantes diz: "Eu queria ir para QUALQUER outro lugar, tô cansada. Sério!” (R.1). O mesmo sentimento é compartilhado por um estudante vindo de outra instituição Federal de ensino superior. A falta de acolhimento vivido por esses estudantes é geradora de conflito e evasão. 
(R1) - Julia Bete “...O W. que entrou com a gente ... junto no PROVAR, ele era da Federal de Pelotas...e ele não tava bem aqui, ele não tava bem...ele não conseguia se inserir nesse grupo, aí decidiu voltar lá pra universidade da onde ele veio...ele falava que sentia falta ... ((ruído)) desse acolhimento".

O sentimento de estranhamento, de não pertencimento e de falta de acolhimento marca fortemente o constrangimento sentido por essas estudantes. Para elas, serem acolhidas e aceitas amenizaria a questão de evasão e desistência.

A culpa e o fracasso é outro ponto surgido nas discussões. As estudantes relatam sentirem-se incapazes e culpadas por não conseguirem se inserir nos grupos, por não conseguirem fazer novas amizades, nem acompanhar o ritmo da universidade. Algumas estudantes relatam ter procurado ajuda psicológica profissional por acharem que elas eram o problema. "O fenômeno da responsabilização da vítima (Blame the victim) que se manifesta pela falácia da "menos-valia” dos alunos; pela entrada por vias escusas como a porta-dosfundos” (Baibich-Faria \& Arco-Verde, 2006, p. 7), são fenômenos recorrentes entre as estudantes ingressantes pelo PROVAR. Após as Rodas de Conversas e troca de experiências proporcionadas pelos encontros, constatou-se que esse sentimento era compartilhado por todas, aliviando assim, o peso da responsabilização pelas dificuldades encontradas. O amparo no sofrimento mostra que há ajuda entre os pares. O grupo serve de apoio nas horas de confusão, rejeição e dificuldades.

(R. 1) Julia Bete “... eu tava conversando com a outra G. lá na casa dela e ela tava me falando, que ela faz análise lá com um... junguiano e tal e ela tava muito mal, conversando com ele dizendo que não aguentava mais, que achava que era ela que era o problema diante toda essa situação” =

Jane. - “Eu achava isso também, quando eu entrei, eu achava que era EU o problema, que eu não conseguia fazer amizade, assim, nem nada” = Julia Bete - "Eu também achava!”

$\mathrm{O}$ fato de não ter entrado pelo vestibular parece ser considerado um ponto negativo pelas estudantes. Para elas a entrada via PROVAR é visto por alguns como um meio alternativo, com menos exigência, portanto menos merecedor do status do dito aluno Federal. O sentimento de ser burro, por tirar notas mais baixas comparado àquelas tiradas na instituição de origem, bem como a crença de não ter a mesma capacidade dos outros estudantes que entraram pelo vestibular tradicional foram relatados. 
No entanto, os resultados do estudo sobre o PROVAR, bem como outras políticas públicas de acesso diferenciado (Baibich-Faria \& Arco-Verde, 2006; Machado \& Pan, 2014; Machado \& Pan, 2016; Branco \& Pan, 2016; Pan \& Zonta, 2017) mostram que muitas vezes esses estudantes do PROVAR buscam provar que são capazes e acabam se destacando em seus desempenhos e resultados.

(R. 1) Julia Bete - "Mas sabe uma coisa, assim que eu fiquei me sentindo muito mal quando aconteceu, muito mal mesmo... eu tava lá com um colega...e eu falei: nossa, eu não entendi porque eu fui mal. Eu não tinha ido mal, mas pra mim eu tinha...aí ele falou " "ah, mas e na (universidade X)? Você tirava notas boas?”,, eu falei, “"Sim ... sempre tirei””, “"e no ensino médio? Você tirava notas boas?” ”. Aí eu falei, “ “olha, no ensino médio eu não era uma aluna muito aplicada, não!”” ““Ah, então, viu?””. Então a questão, tipo, eu não entendi o que ele quis dizer, ele foi, tipo, tentar argumentar de que todos os conhecimentos que eu tive no ensino médio, passar no vestibular, que EU não consegui passar no vestibular”.

O sentimento de exclusão e de falta de apoio foram temas recorrentes durante as Rodas. As estudantes relatam que esse fenômeno não ocorre apenas em relação aos alunos transferidos pelo PROVAR, mas também estudantes ingressantes por meio das COTAS e outros programas de incentivo do Governo.

(R.1) Gina. - “... ela não conseguir muitas vezes acompanhar o ritmo da universidade, por não ter tido essa base muito boa, sabe, eu acho que acaba excluído aqui... Eu vejo, tipo, ninguém quer fazer trabalho com essas pessoas sabe tipo, tu vê "ah ela não vai fazer direito, então não vou me estressar, deixa ela de lado. Tipo, eu me estressava muito fazendo trabalho com ela, muito assim, mas também não ia dizer que não. Teve uma que saiu do grupo, ficou estressada porque ela não sabia fazer os troços direito...”

No caso acima, Gina fala de sua própria reação frente a uma colega, ingressante beneficiaria do Programa de COTAS, a qual apresentava muitas dificuldades para realizar trabalhos acadêmicos e explica também ter se sentido impaciente ao ajudar a colega, assim como outros fizeram. Todavia, ela acolheu e tentou ajudar a colega em questão, possivelmente pelo fato de ela mesma ter vivenciado a rejeição e exclusão, mesmo que de uma forma diferente. Novamente, a solidariedade entre os pares é um modo de sobrevivência desses estudantes dentro da universidade. A dor que surge pela desigualdade social é compartilhada e compreendida pelos pares. 


\section{Rodando a roda}

Sabemos que cada momento histórico priorizou ou desvalorizou alguma emoção humana, alguns exemplos são a vergonha e a culpa. Através do olhar expiatório utilizado como estratégia de controle e coerção social, o homem pôde produzir no outro sentimentos particularistas como ferramenta de controle. Sawaia (2001) fala sobre a dor e a vergonha, sentimentos morais infringidos por uma idealização política separatista e excludente. "O sofrimento é a dor mediada pelas injustiças sociais” (p. 102). Apenas aqueles que vivem a situação de exclusão a sentem como dor. As emoções humanas, também decorrentes de injustiças sociais são fenômenos históricos para a referida autora (2001), seu conteúdo e qualidade estão em constante constituição. A autora defende o uso das emoções, não como instrumento de vergonha, culpa e controle social, mas como “(...) constitutiva do pensamento e da ação (...) matéria-prima básica à condição humana” (p. 100).

Segundo Pan (2003), a permanente problematização acerca das complexas experiências do cotidiano, assim como das políticas públicas de acesso diferenciado (machado \& Pan, 2016) são necessárias devido ás diversas práticas sociais e comportamentos consequentes. É por meio da palavra que os valores são explicitados e confrontados. Ela é qualificada pela maneira como as relações de alteridade se entrelaçam, cuja dinâmica, qualidade e conteúdo se revelam e se determinam nas relações sociais. "Portanto, o sofrimento ético-político retrata a vivência cotidiana das questões sociais dominantes (...), especialmente a dor que surge da situação social de ser tratado como inferior, subalterno, sem valor (...)” (Sawaia, 2001, p. 102). A emoção destacada por Sawaia (2001) serve como "potência de ação” (p. 110), isso é, ressaltar o papel positivo das emoções na luta por valores éticos, como também por meio da ação. No caso desse trabalho, realizou-se tal ação por meio das Rodas de Conversas proposta pelo projeto PermaneSendo, para o enfrentamento da exclusão, assim como as demais injustiças sociais levantadas nessa pesquisa.

Mancebo (2004) alerta para os riscos da lógica da produtividade empresarial infiltradas no ensino superior público, a qual quantifica as atividades e elege a "competitividade" como mola mestra do trabalho acadêmico (p. 15). Uma cultura de competição excessiva na UFPR também foi apontada pelas estudantes.

A dificuldade para se locomover dentro dos labirintos da universidade, dificultando que os estudantes caminhem com suas próprias pernas (Baibich-Faria \& Arco-Verde, 2006), bem 
como a íngreme escadaria na porta de entrada da universidade em questão pode simbolizar a supremacia, historicamente disseminada entre àqueles que têm condições de chegarem até o ‘topo’ por si só (os mais fortes sobrevivem) e os outros que não conseguiram por conta própria.

A competitividade instaurada pela forma de seleção para as atividades acadêmicas obrigatórias também pode ser destacada, pois insere-se na mesma lógica capitalista. A fala de um professor para uma das estudantes denúncia esse discurso quando diz:

(R.2) "a universidade pública é para os fortes, quem aguentar a pressão aguenta o mercado de trabalho ... a universidade pública é isso, é para os fortes, quem aguenta, aguenta, quem não aguenta vai acabar saindo ... e daí a estrutura (falando do prédio) mostra como é: não tem lugar para sentar, não tem conforto... Você tem que se virar do jeito que tem, então pra realmente testar quem é o forte, pra ver quem vai aguentar.

As estudantes compartilham o sentimento de frustração e sofrimento na tentativa de se adaptarem e de se enquadrarem ao dito perfil do universitário da UFPR, na suposição de que seriam aceitas.

No entanto, apesar dos benefícios que a universidade pública proporciona, como maiores oportunidades de pesquisa e estudo, as estudantes entendem que a experiência de ser um aluno transferido pelo PROVAR não é algo que recomendariam para outros colegas. Os benefícios de ser transferido pelo PROVAR não valem a pena, para elas.

(R.2) Gina. - “Comecei a desabar minha vida ali pra ele (um estudante de uma faculdade particular interessado na transferência externa do PROVAR), falei “"não vale a pena, mas olha, tem certeza, tu precisa mesmo?” ... nossa desabei!”

Lamentavelmente, a entrada ao ensino superior público pelo PROVAR mostrou-se, pelos relatos dessas estudantes, ser uma experiência frustrante e solitária. O que se constatou foi desamparo, desânimo e o sentimento de falta de mérito pela forma de ingresso. As estudantes sentem-se fracassadas mediante a competição e pela desvantagem acadêmica, porém tendo o desejo de serem aceitas, consideradas iguais, competentes e reconhecidas. Desejam comprovar seus méritos e esforço na competitividade (natural) acadêmica e profissional, a partir de oportunidades igualitárias.

O trabalho realizado desencadeou algumas ações dos próprios estudantes do PROVAR, consolidando-se num coletivo de estudantes da UFPR que passaram a organizar debates e conversas expositivas sobre o que é o PROVAR (alguns estudantes desconheciam o programa), 
possibilitando a inclusão das demandas e necessidades dos estudantes vindos do PROVAR nas pautas das comissões estudantis, para que juntos pudessem buscar mudanças e melhores condições para os atuais e futuros colegas. O planejamento de ações como recepções oficiais foram consideradas como indispensáveis para novos ingressantes de políticas diferenciadas de acesso à UFPR, bem como o acolhimento por pares, orientação sobre as questões burocráticas da universidade, deveres e responsabilidades, entre outras.

\section{Considerações finais}

O objetivo principal dessa pesquisa foi analisar os efeitos de sentido de uma política de ocupação de vagas ociosas, conhecida como PROVAR, na produção da subjetividade de um grupo de estudantes, seus beneficiários. Por meio das Rodas de conversa foi possível ressignificar discursos que constituem identidades, sentidos e modos de subjetivação das participantes.

As Rodas de Conversa, a partir de uma perspectiva do dialogismo bakhtiniano abriu espaço para que as vozes das estudantes pudessem ser ouvidas e onde a troca de experiências e sentimentos pudessem ser resinificados por meio do debate, do reposicionamento e enfrentamento na “arena de vozes sociais” (Machado \& Pan, 2016, p. 485).

O conceito ético-político usado por Sawaia (2001), valoriza as emoções sentidas pelas estudantes ao elucidar, por meio da afetividade e sentimentos, a posição de excluídas pelo discurso da inclusão, dentro da instituição.

O compartilhar dos sentidos de ser um estudante transferido pelo PROVAR e os emoções produzidas a partir dessa experiência serviu de potencial de ação e posicionamento "ético-político” (Machado \& Pan, 2016, p. 485) das estudantes para que estas pudessem desenvolver o protagonismo estudantil, construído coletivamente, levando adiante formas de superação dos diversos obstáculos encontrados na realidade acadêmica, para novos grupos de beneficiários dessa política pública.

A educação, a reflexão e a desconstrução de atitudes e comportamentos sociais preconceituosos são algumas das missões que a universidade pública deve buscar em seu papel social, a fim de possibilitar novas significações e sentidos na vida daqueles que passam pela universidade e que reproduzirão ideais sociais adquiridos e construídos ao longo de suas jornadas acadêmicas. As Rodas de Conversa também possibilitaram “instrumentalizar os 
sujeitos em formação para o enfrentamento da crise ética que caracteriza a sociedade contemporânea” (Baibich-Faria \& Arco-Verde, 2006, p. 14).

É necessário avançar em direção ao conhecimento e elucidação das experiências desses alunos para que a partir delas, novas estratégias possam ser (re)pensadas para proporcionar a qualidade da formação profissional dos acadêmicos.

\section{Referências}

Amorim, M. (2002). Vozes e silêncio no texto de Pesquisa em Ciências Humanas. Cadernos de pesquisa, 116, 07-19. Recuperado em de https://dx.doi.org/10.1590/S010015742002000200001

Baibich-Faria, T. M., \& Arco-Verde, Y. F. S. (2006). O Preconceito em uma instituição de ensino superior: um estudo sobre o processo de ocupação de vagas remanescentes na Universidade Federal do Paraná. Revista da Rede de Avaliação Institucional da Educação Superior, 2006.2 Recuperado de http://educa.fcc.org.br/pdf/aval/v11n03/v11n03a08.pdf

Branco, P. I,, \& Pan, A. G. S. P. (2016). Rodas de conversa: uma intervenção da psicologia educacional no curso de medicina. Revista Psicologia: Teoria e Prática. 18(3), pp. 156-167.

\section{http://dx.doi.org/10.5935/1980-6906/psicologia.v18n3p156-167}

Fávero, M. L. A. (2006). A universidade no Brasil: das origens à reforma universitária de 1968. Educar. (28), pp. 17-36. Recuperado de http://www.scielo.br/pdf/er/n28/a03n28

Freitas, M. T. D. A. (2002). A abordagem sócio-histórica como orientadora da pesquisa qualitativa. Cadernos de Pesquisa, (116), pp. 21-39. Recuperado de http://www.scielo.br/scielo.php?script=sci_arttext\&pid=S0100-15742002000200002

Freitas, M. T. D. A., Bernardes, A. S., Pereira, A; P. M. S., Pereira, M. L. (2009). O sujeito nos textos de Vigotski e do Círculo de Bakhtin: implicações para a prática da pesquisa em educação. Fractal: Revista de Psicologia, 27(1), pp. 50-55. Recuperado de http://www.uff.br/periodicoshumanas/index.php/Fractal/article/view/1355

Hall, S. A. (2014) Identidade Cultural na Pós-Modernidade. (T. S. Tadeu, Trad.). 12. ed. Rio de Janeiro: DP\&A.

Jobim e Souza, S. \& Albuquerque, E. D. P. (2012). A pesquisa em Ciências Humanas: uma leitura bakhtiniana. Revista de Estudos do Discurso. 7(2), pp. 109-122. Recuperado de http://www.scielo.br/pdf/bak/v7n2/08.pdf 
Machado, J. (2011). Entre frágeis e durões: assistência estudantil e seus efeitos nos modos de subjetivação de bolsistas permanência da Universidade Federal do Paraná. (Dissertação de mestrado). Setor de Ciências Humanas, Letras e Artes, Universidade Federal do Paraná, Curitiba, PR, Brasil. http://www.humanas.ufpr.br/portal/psicologiamestrado/files/2014/12/relação-dedissertações-por-orientador-ate-15-02-2016.pdf

Machado, J. P., \& Pan, M. A. G. de S. (2012). Do Nada ao Tudo: políticas públicas e a educação especial brasileira. Educação \& Realidade, 37(1), pp. 273-294. Recuperado de http://seer.ufrgs.br/educacaoerealidade/article/view/16130/16048

Machado, J. P., \& Pan, M. A. G. de S. (2013). Assistência estudantil: sentidos em (trans)formação. In N. da L. Ferrarini \& D. Ruppel (Orgs.), Inclusão racial e social: considerações sobre a trajetória da UFPR (pp. 261-288). Curitiba: Ed. UFPR.

Machado, J. \& Pan, M. A. G. S. (2014). Política pública e subjetividade: a assistência estudantil na universidade. Textos \& Contextos. 13(1), pp. 184 - 198. Recuperado de http://revistaseletronicas.pucrs.br/ojs/index.php/fass/article/view/15929

Machado, J. \& Pan, M. A. G. S. (2016). Direito ou benefício? Política de assistência estudantil e seus efeitos subjetivos aos universitários. Estudos de Psicologia, 21(4), pp. 477-488. http://dx.doi.org/10.5935/1678-4669.20160046

Pan, M. A. G. S. (2003). Infância, discurso e subjetividade: uma discussão interdisciplinar para uma nova compreensão dos problemas escolares. (Tese de Doutorado). Setor de Ciências Humanas, Letras e Artes, Universidade Federal do Paraná, Curitiba, PR, Brasil.

Pan, M. A. G. S. (2013). Identidade, políticas inclusivas e universidade contemporânea: desafios à Psicologia Brasileira. (Programa de Mestrado em Psicologia). Setor de Ciências Humanas, Letras e Artes, Universidade Federal do Paraná, Curitiba, PR, Brasil.

Pan, M. G. S., Zonta \& Tovar, G. A. (2015). Plantão institucional: Relato de experiência de uma intervenção psicológica na UFPR. Psicologia em estudo. 20(4), pp. 555-562. Recuperado de http://periodicos.uem.br/ojs/index.php/PsicolEstud/article/view/27594

Pan, M. A. G. S. (2016). Identidade, políticas inclusivas e universidade contemporânea: desafios à Psicologia brasileira. (Programa de Mestrado em Psicologia $2^{\mathrm{a}}$ edição). Setor de Ciências Humanas, Letras e Artes, Universidade Federal do Paraná, Curitiba, PR, Brasil.

Sawaia, B. B. (2001). O Sofrimento Ético-Político como categoria da análise da dialética exclusão/inclusão. In Sawaia, B. B. As Artimanhas da Exclusão: 2. ed. pp. 97 - 118. Petrópolis, R.J.: Vozes.

Sawaia, B. B. (2001). Identidade - Uma ideologia separatista? In Sawaia, B. B. As Artimanhas da Exclusão: 2. ed. pp. 129 - 140. Petrópolis, R.J.: Vozes. 